\title{
Article \\ A Low-Cost Prestress Monitoring Method for Post-Tensioned RC Beam Using Piezoelectric-Based Smart Strand
}

\author{
Thanh-Cao Le ${ }^{1,2,3}$, Thi Tuong Vy Phan 4,5 , Trung-Hau Nguyen ${ }^{2,6}$, Duc-Duy Ho ${ }^{1,2, * \mathbb{D}}$ \\ and Thanh-Canh Huynh $7,8, *$ (D)
}

1 Faculty of Civil Engineering, Ho Chi Minh City University of Technology (HCMUT), 268 Ly Thuong Kiet, District 10, Ho Chi Minh City 700000, Vietnam; 1880698@hcmut.edu.vn

2 Vietnam National University Ho Chi Minh City (VNU-HCM), Linh Trung Ward, Thu Duc District, Ho Chi Minh City 700000, Vietnam; haunguyen85@hcmut.edu.vn

3 Faculty of Civil Engineering, Nha Trang University, Nha Trang 650000, Vietnam; caolt@ntu.edu.vn

4 Center for Advanced Chemistry, Institute of Research and Development, Duy Tan University, Danang 550000, Vietnam; phanttuongvy4@duytan.edu.vn

5 Faculty of Environmental and Chemical Engineering, Duy Tan University, Danang 550000, Vietnam

6 Faculty of Applied Science, Ho Chi Minh City University of Technology (HCMUT), 268 Ly Thuong Kiet, District 10, Ho Chi Minh City 700000, Vietnam

7 Center for Construction, Mechanics and Materials, Institute of Research and Development, Duy Tan University, Danang 550000, Vietnam

8 Faculty of Civil Engineering, Duy Tan University, Danang 550000, Vietnam

* Correspondence: hoducduy@hcmut.edu.vn (D.-D.H.); huynhthanhcanh@duytan.edu.vn (T.-C.H.)

check for updates

Citation: Le, T.-C.; Phan, T.T.V.; Nguyen, T.-H.; Ho, D.-D.; Huynh, T.-C. A Low-Cost Prestress

Monitoring Method for Post-

Tensioned RC Beam Using Piezoelectric-Based Smart Strand. Buildings 2021, 11, 431. https:// doi.org/10.3390/buildings11100431

Academic Editors: Jose Antonio Lozano-Galant and Bruno Briseghella

Received: 19 August 2021

Accepted: 22 September 2021

Published: 25 September 2021

Publisher's Note: MDPI stays neutral with regard to jurisdictional claims in published maps and institutional affiliations.

Copyright: (c) 2021 by the authors. Licensee MDPI, Basel, Switzerland. This article is an open access article distributed under the terms and conditions of the Creative Commons Attribution (CC BY) license (https:/ / creativecommons.org/licenses/by/ $4.0 /)$.

\begin{abstract}
This study proposes a cost-effective prestress monitoring method for post-tensioned reinforced concrete $(\mathrm{RC})$ beams using a smart strand. Firstly, the concept of a piezoelectric-based smart strand and its implementation for prestress force monitoring are developed. The smart strand is prepared by embedding inexpensive and high-sensitivity electromechanical impedance (EMI) sensors in a steel strand. Next, the feasibility of the proposed method is experimentally verified for prestress force monitoring of a simple supported post-tensioned RC beam. A smart strand prototype is fabricated and embedded into a $6.4 \mathrm{~m} \mathrm{RC}$ beam which is then prestressed with different levels. For each prestress level, the EMI responses of the smart tendon are measured and the EMI features are extracted for prestress force monitoring. The results showed that the EMI signals of the smart strand showed strong resonant peaks that varied sensitively to the prestress level of the beam. The prestress change in the prestressed RC beam was successfully estimated by using linear regression models of the EMI features.
\end{abstract}

Keywords: piezoelectric-based smart strand; EMI sensor; EMI technique; prestress monitoring; RC beam; prestressed structures

\section{Introduction}

Structural health monitoring (SHM) of prestressed reinforced concrete (RC) structures has increasingly received significant interest from civil engineers, maintenance crews, and researchers. In these structures, the value of the prestress (PS) force is a key parameter for the evaluation of structural performance [1]. After the completion of the construction process, the strand may suffer short-term and long-term PS loss over time as the result of multiple causes (e.g., concrete shrinkage and creep, corrosion and strand relaxation, flexural cracks). A severe drop in the PS force, if not timely detected, will significantly influence the bearing capacity of the prestressed structure, carrying the potential of catastrophic failure $[2,3]$.

Since the 1990s, research efforts have been made to develop SHM techniques for PS force monitoring of prestressed structures. One of the first attempts was conducted by Saiidi et al. [4]. In their research, they analyzed the effect of the PS force on the 
dynamic properties of $\mathrm{RC}$ beams and concluded that periodic monitoring of the dynamic characteristics can be useful to discriminate the PS losses. Based on this pioneering study, Kim et al. [5] developed a theoretical formula to estimate the PS loss of an unbonded strand in a prestressed beam by using the shift in modal frequencies. However, PS loss, in most cases, causes only small changes in the vibration frequencies of the prestressed $\mathrm{RC}$ structure. Since a tiny alternation in structural parameters of a prestressed structure (e.g., the mass, the boundary condition, geometric properties) can also result in frequency variations, the prediction of the actual PS force based on the vibrational frequency of the prestressed structure becomes less accurate.

Other researchers have focused on developing local SHM techniques with a high level of sensitivity to the loss of PS force. For example, Wang et al. [6] developed a PS force monitoring method for stay cables using elasto-magnetic (EM) sensors. The EM-based technique is based on the relationship between magnetic properties and the local stress of a steel strand [6,7]. Halvonik et al. [8] applied EM sensors for long-term PS loss monitoring in prestressed concrete beams. The acousto-elastic (AE)-based technique utilizing wave propagation characteristics was also developed for PS force monitoring [9]. Chaki and Bourse [10] derived acoustoelastic formulas together with acoustoelastic measurements to assess the service PS values of seven-wire steel strands. Despite their high sensitivities to PS loss, these local techniques require expensive and precise instruments and do not appear feasible for real-time SHM. Other research groups attempted to monitor the PS force of prestressed structures by measuring the strain of prestressed strands [11-14]. Kim et al. [15] developed a smart tendon by embedding a fiber Bragg grating (FBG) sensor into a sevenwire steel strand for anchor force monitoring. Although the FBG-based technique has high precision and suitability for real-time SHM, it is not cost-effective because of expensive FBG-based smart strands and optical sensing interrogator. State-of-the-art membrane electrostatic sensors could also be promising candidates for PS force monitoring [16-18]. However, more numerical and experimental investigations are needed to prove this idea.

Among the currently available local methods, the electromechanical impedance (EMI)based technique has been considered as an innovative and low-cost SHM tool for PS assessment of prestressed structures [19-24]. The EMI-based technique was first developed for damage detection and it soon received significant interest from many researchers because of its unique advantages. The technique uses an inexpensive, lightweight, fast response and robust piezoelectric transducer (e.g., PZT_lead zirconate titanate) to obtain the EMI response of a host structure that varies sensitively to structural damage [25]. The use of short wavelengths and high frequencies allow the technique to detect any structural changes at a very early stage. The technique has a wide range of applications from simple to complex structures. Besides, currently available EMI sensing devices are low-cost, autonomous and have wireless communication, making the technique feasible for real-time and online SHM cost-effectively [26-31]. One of the first applications of the technique for PS force monitoring was carried out by Kim et al. [32]. In their study, the PS loss was monitored through the change in EMI responses of the anchorage. However, due to the high stiffness of the anchorage, it is often hard to capture strong EMI responses. To overcome this drawback, a smart PZT washer was developed and inserted into the connection between the anchor block and the bearing plate [33]. However, another issue has been raised regarding the influence of the inserted washer on the overall performance of the prestressed anchorage, which requires deeper analyses. Thus, some researchers have designed alternative mountable piezoelectric devices for EMI-based PS force monitoring $[34,35]$. Despite these previous research attempts, there is still a need to develop a high-sensitivity EMI-based technique for low-cost SHM of prestressed RC structures.

Inspired by the concept of the FBG-based smart tendon and the advantages of the low-cost EMI-based technique, we develop a cost-effective prestress monitoring method for post-tensioned RC beams using the piezoelectric-based smart strand. The main idea is to design an inexpensive and high-sensitivity EMI sensor and attach it to a steel strand to capture strain variations induced by the PS loss. To obtain this objective, the following 
approaches are performed. Firstly, the concept of a piezoelectric-based smart strand and its implementation for PS force monitoring are developed. Secondly, the feasibility of the proposed method is experimentally verified for prestress force monitoring of a simple supported post-tensioned RC beam. A smart strand prototype is fabricated and embedded into a $6.4 \mathrm{~m}$ steel strand. The EMI responses of the smart strand are measured under different PS levels and the EMI features are then extracted for PS force monitoring. The linear regression models of the EMI features are established to predict change in the prestressed RC beam. It should be noted that the EMI sensor can be fabricated with a low cost and its EMI response can be obtained by currently available inexprensive EMI analyzers. Therefore, the proposed system is cost-effectiveness as compared to the previous systems.

\section{Piezoelectric-Based Smart Strand for Post-Tensioned RC Beam}

Previous studies have shown the prospect of stress identification by EMI measurement $[36,37]$. Based on these studies, we designed the concept of the 'piezoelectric-based smart strand', which is a steel strand embedded with low-cost and high-sensitive EMI sensors. Figure 1 shows a framework for cost-effective EMI-based PS force monitoring of a post-tensioned RC beam that is accomplished through the following steps: (1) design the piezoelectric-based smart strand for a prestressed RC beam; (2) periodically measure the EMI response of the smart strand by using low-cost and compact EMI analyzers [26-31]; (3) extract the EMI features (such as peak frequency, peak magnitudes, damage metrics); and (4) monitor the PS force and estimate the PS change by using the extracted EMI features.

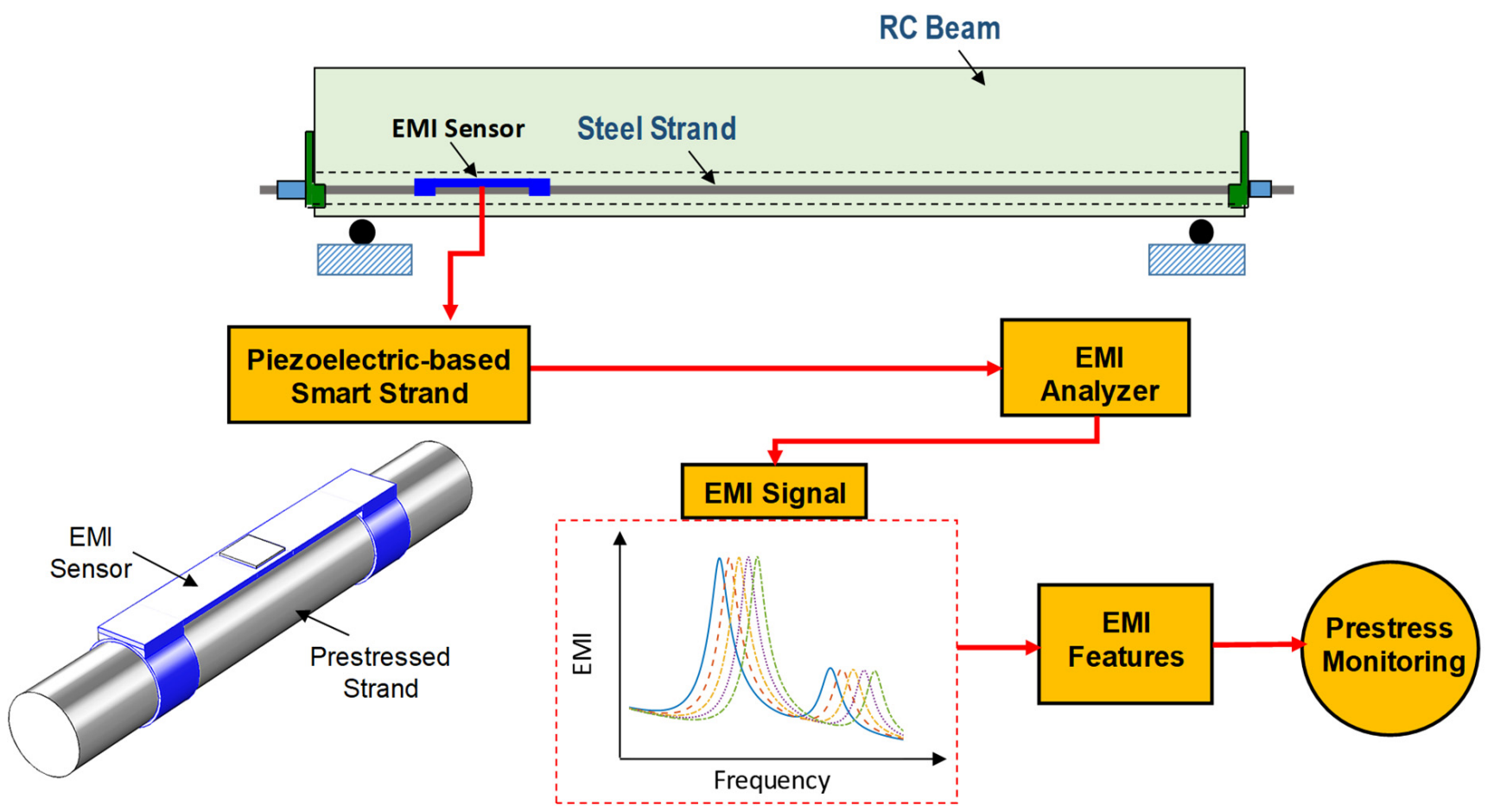

Figure 1. Framework for PS force monitoring using the concept of piezoelectric-based smart strand.

\subsection{Conceptual Design of Piezoelectric-Based Smart Strand}

Figure 2 depicts the conceptual design of a piezoelectric-based smart strand. Traditionally, the PZT patch is directly attached to the surface of the host structure to measure EMI responses in the EMI-based technique. The target surface should be flat to secure the contact between the PZT and the host structure and reduce the attenuation of the elastic waves transmitting through the structure during the piezoelectric excitation. However, the 
rugged surface of the steel strand is not ideal for direct attachment of the PZT. To address this issue, we install the PZT patch on an aluminum substrate to create the portable EMI sensor [38-41]. This idea was initiated by Annamdas et al. [42] and improved in [19,43] to achieve damage-sensitive resonant frequency bands for impedance-based SHM.

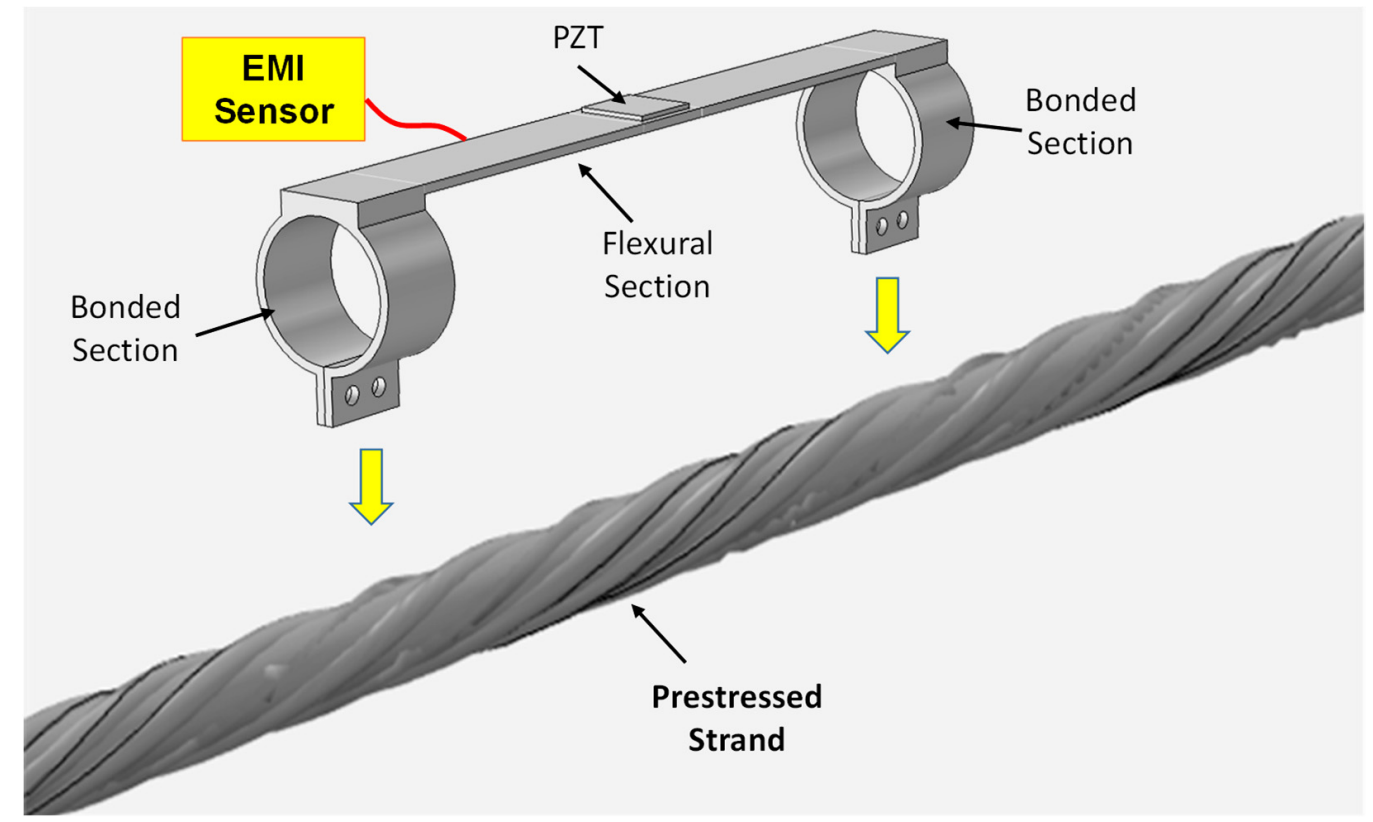

Figure 2. The conceptual design of the piezoelectric-based smart strand.

The design of the EMI sensor is depicted in Figure 2. The sensor is composed of a substrate structure and a PZT. The substrate is a plate-like structure with a middle flexural segment and two outside bonded segments. The middle section is equipped with a PZT patch while the outside segments are designed as joint rings to clamp the piezoelectric device on the strand. The middle segment should be thin enough to enhance the piezoelectric deformation of the PZT. The joint rings allow the EMI sensor to be conveniently installed on and removed from the host strand. It should be noted that the PZT is not exactly installed at the middle of the flexural section, but slightly deviated from the center to activate more modes of the substrate. The dimensional parameters of the EMI sensor can be adjusted to create strong EMI responses in any pre-defined frequency bands [44]. This is one of the most important features of the proposed EMI sensor.

\subsection{Theoretical Feasibility of the Piezoelectric-Based Smart Strand}

The prestress (PS) force applied to the smart strand induces the axial tensile load (T) in the flexural part of the EMI sensor through the two outside rings (see Figure 3). The EMI response of the smart strand contains the information not only of the EMI sensor but also the PS force. Once the PS force of the smart strand is altered, the tensile stress of the sensor is varied, resulting in change in the EMI response. When a harmonic voltage is applied on the PZT patch, there are coupling vibrations between the PZT and the flexural part. Figure 3 shows an example of the piezoelectric deformation of the substrate at the first bending natural frequency. The PZT is bent with the motion of the middle segment while the outside parts remain fixed on the host structure. 


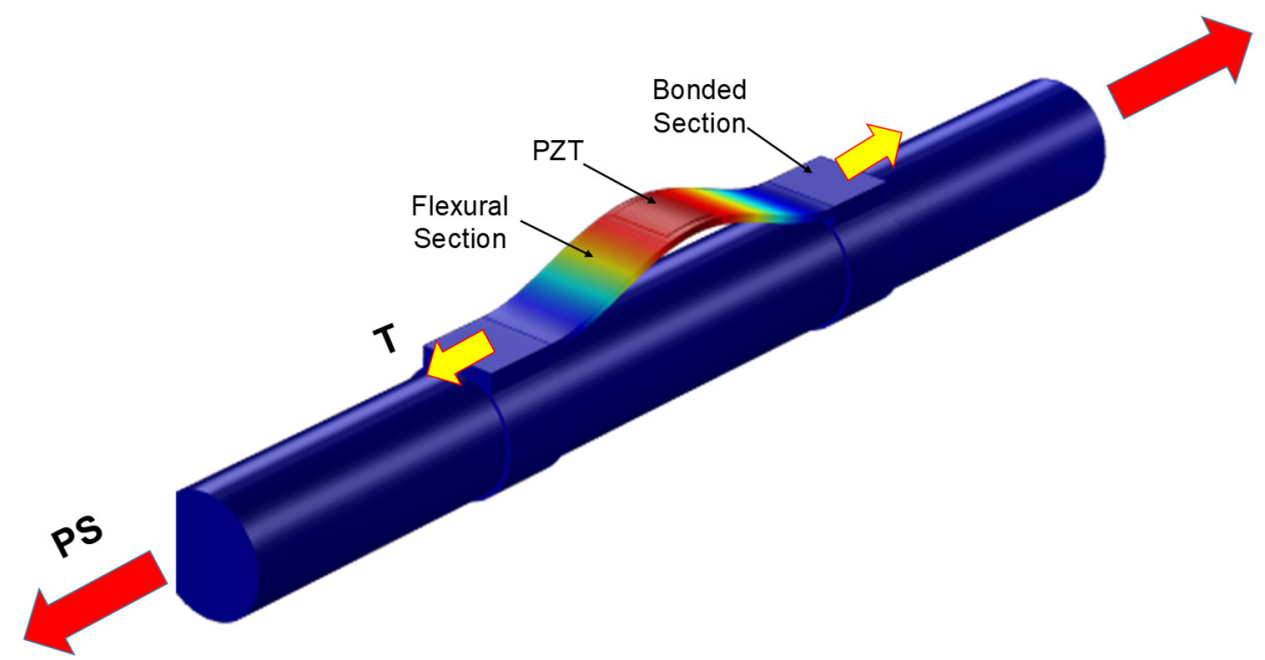

Figure 3. The 1st bending deformation of the EMI sensor due to the piezoelectric effects.

The interaction between the PZT and the substrate structure can be theoretically described by a simplified EMI model, as depicted in Figure 4. Under the effect of applied voltage $\mathrm{V}$, the PZT is expanded and its deformation drives the substrate structure through the contact force F. The ability to resist this piezoelectric deformation is regarded as the mechanical impedance of the structure, which can be computed as the rate between the exciting force $\mathrm{F}$ and the velocity $v_{s}$ at the PZT driving point, as follows [45]:

$$
Z_{s}(\omega)=\frac{F(\omega)}{v_{s}(\omega)}=c_{s}+m_{s} \frac{\omega^{2}-\omega_{n}^{2}}{\omega} i
$$

where $m_{s}, c_{s}$, and $k_{s}$ are the mass, the stiffness, and the damping parameters of the substrate structure; and $\omega$ is the angular frequency which is often designed in high-frequency bands $[46,47]$.

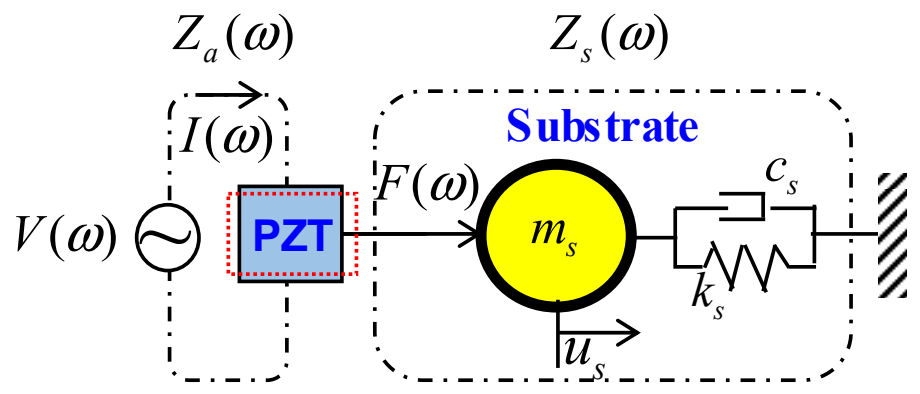

Figure 4. The simplified model of the EMI sensor; the term $u_{S}$ is the displacement of the mass $m_{s}$.

In real EMI-based applications, the mechanical impedance of the substrate is not possible to measure. Instead, we measure the output current $I$ of the system and the EMI response is computed as the rate between the applied voltage $V$ and the current $I$. Liang et al. [45] demonstrated that the EMI response of the PZT-substrate system, $Z(\omega)$ is a combined function of the structural impedance of the substrate $\left(Z_{S}(\omega)\right)$, and the structural impedance of the PZT patch $\left(Z_{a}(\omega)\right)$, as follows:

$$
Z(\omega)=\frac{V(\omega)}{I(\omega)}=\left\{i \omega \frac{w_{a} l_{a}}{t_{a}}\left[\hat{\varepsilon}_{33}^{T}-\frac{1}{Z_{a}(\omega) / Z_{s}(\omega)+1} d_{3 x}^{2} \hat{Y}_{x x}^{E}\right]\right\}^{-1}
$$

where $\hat{Y}_{x x}^{E}=(1+i \eta) Y_{x x}^{E}$ is the complex Young's modulus of the PZT patch at zero electric field; $\hat{\varepsilon}_{x x}^{T}=(1-i \delta) \varepsilon_{x x}^{T}$ is the complex dielectric constant at zero stress; the parameters $\eta$ and $\delta$ are structural damping loss factor and dielectric loss factor of the PZT, respectively; 
$d_{3 x}$ is the piezoelectric coupling constant in $x$-direction at zero stress; and $w_{a}, l_{a}$, and $t_{a}$ are the width, length, and thickness of the PZT, respectively. From Equations (1) and (2), it is shown that the measured EMI response provides information about the resonant frequencies of the EMI sensor.

On the other hand, it is well-known that the natural frequency of the substrate structure is proportional to the axial load [36,37]. Supposing that the flexural part of the sensor is a simple supported beam and has the Young modulus $E_{s}$, the moment of inertia $I_{S}$, the length $l_{s}$, the mass density $\rho_{S}$ and the cross-section area $A_{s}$, the $n$-th natural frequency of the transverse vibration of the sensor under tension could be expressed $[36,37]$ as follows:

$$
\omega_{n}=\sqrt{\frac{E_{s} I_{s}}{\rho_{s} A_{s}}\left(\frac{n \pi}{l_{s}}\right)^{2}\left[\left(\frac{n \pi}{l_{s}}\right)^{2}+\frac{T}{E_{s} I_{s}}\right]}
$$

where the term $T$ indicates the tensile load in the EMI sensor, which relates to the PS force of the smart strand based on the following expression:

$$
T=\xi \frac{E_{s} A_{s}}{E_{s t} A_{s t}} P S
$$

where the terms $E_{s t}$ and $A_{s t}$ are the Young's modulus and the cross-section area of the host strand; $\xi$ is the shear-lag index, representing the load transfer capability of the prestressed strand to the EMI sensor through the joint rings. $\xi=1$ indicates a situation that the PS force is completely transferred to the sensor, while $\xi=0$ indicates no PS force transfer. In practice, $\xi$ ranges from 0 to 1 .

Equations (1), (3) and (4) show that the mechanical impedance of the substrate varies with the PS force of the strand while the measured EMI response at a particular frequency is a function of the mechanical impedance, according to Equation (2). Consequently, the measured EMI response in the frequency domain is expected to vary with the PS load. As the PS force is altered, the resonant impedance peaks of the EMI sensor are shifted. By observing the alternation of the EMI response, the change in the PS force of the prestressed strand can be identified.

\subsection{PS Monitoring Approaches Using EMI Features}

From the previous works, it is evidenced that the real part of the EMI responses contains the majority of the structural information [46-48], whereas the imaginary part contains more information about the PZT patch and thus is often used to assess abnormal functionalities during SHM [48-51]. In this study, we extract EMI features from the real EMI signals to monitor the PS force. We adopt two common EMI features: root-meansquare-deviation (RMSD), and cross-correlation deviation (CCD) for PS force monitoring. Ideally, the EMI features (i.e., RMSD and CCD) are equal to 0 if the PS force remains unchanged, whereas they are over 0 if the prestressed structure is losing its PS force.

The RMSD index is one of the more widely used damage metrics in the EMI-based technique. It statistically measures the difference between two EMI signals. The RMSD index is obtained by the following expression $[52,53]$ :

$$
\operatorname{RMSD}\left(Z, Z^{*}\right)=\sqrt{\sum_{i=1}^{N}\left[Z^{*}\left(\omega_{i}\right)-Z\left(\omega_{i}\right)\right]^{2} / \sum_{i=1}^{N}\left[Z\left(\omega_{i}\right)\right]^{2}}
$$

in which $Z\left(\omega_{i}\right)$ and $Z^{*}\left(\omega_{i}\right)$ are the EMI signals of the reference (i.e., healthy state) and unknown state (i.e., PS change state), respectively; the term $N$ is the number of swept frequency points; $\omega_{i}$ is the $i$ th swept frequency. 
The CCD index measures the deviation in the pattens of two EMI signals. The formula of the CCD index can be expressed by [54].

$$
\operatorname{CCD}\left(Z, Z^{*}\right)=1-\frac{1}{\sigma_{Z} \sigma_{Z}^{*}} E\left\{\left[Z\left(\omega_{i}\right)-\bar{Z}\right]\left[Z^{*}\left(\omega_{i}\right)-\bar{Z}^{*}\right]\right\}
$$

where $E\{$.$\} is the expectation operation; \bar{Z}$ and $\sigma_{Z}$ are the mean and the standard deviation of EMI signal at the reference state (i.e., healthy); $\bar{Z}^{*}$ and $\sigma_{Z}^{*}$ are the mean and the standard deviation of EMI signal at the unknown state (i.e., PS change).

\section{Experimental Feasibility \\ 3.1. Experimental Setup}

An experiment was performed on a realistic post-tensioned RC beam to evaluate the feasibility of the concept of the piezoelectric-based smart strand for PS force monitoring. Figure 5a shows the setup of the RC beam in the laboratory. The test structure is a $6.4 \mathrm{~m}$ simple supported RC beam prestressed by a seven-wire steel strand. The PS force was introduced into the beam using a stressing device and measured by a load cell. To prepare the piezoelectric-based smart strand, an EMI sensor was fabricated and attached to the naked strand; then the prepared strand was inserted into the RC beam for PS force monitoring, as shown in Figure 5b. The EMI response of the smart strand was measured by an EMI analyzer, the HIOKI 3532-50 LCR Hi-Tester (HIOKI E.E. corporation, Ueda, Nagano, Japan) (frequency range of $42 \mathrm{~Hz}$ to $5 \mathrm{MHz}$, minimum measurement time of $5 \mathrm{~ms}$, 4 simultaneous measurement items).

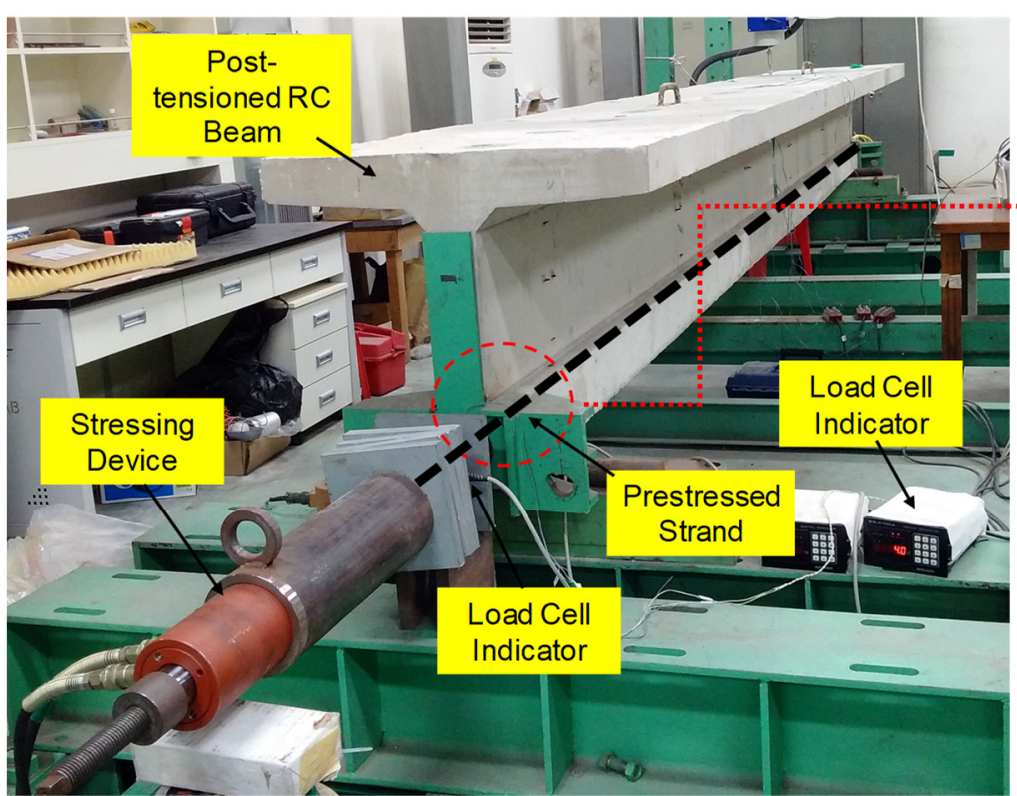

(a) Setup of the post-tensioned RC beam
Piezoelectric-based Smart Strand

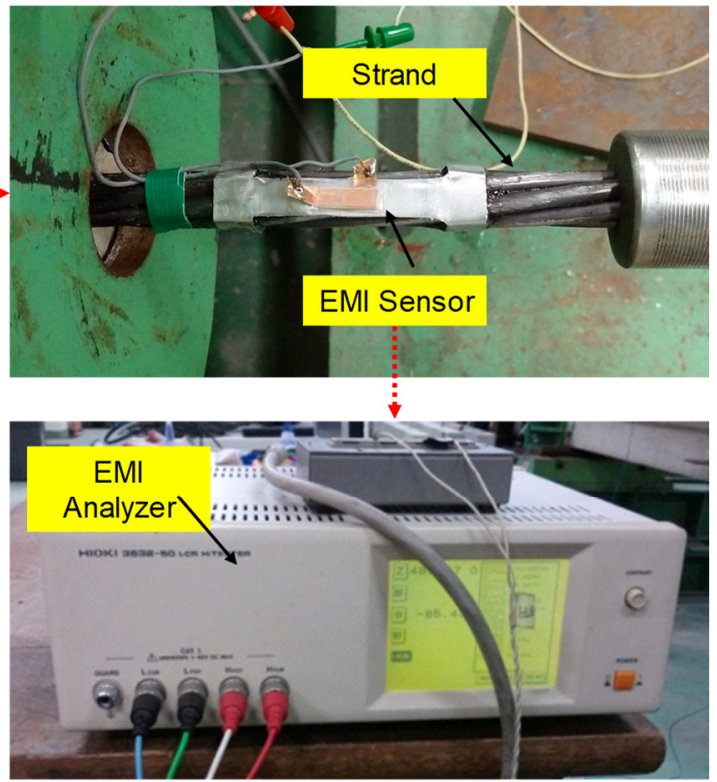

(b) Setup of the smart strand

Figure 5. Experimental setup.

The detailed geometry of the prestressed RC beam can be seen in Figure 6a. The beam has a T-shaped cross-section with a flange of $0.71 \mathrm{~m}$ in width and a web of $0.5 \mathrm{~m}$ in height. The dimensional parameters of the EMI sensor and its location on the strand are depicted in Figure $6 \mathrm{~b}$. The flexural section of the sensor has $10 \mathrm{~mm}$ width, $50 \mathrm{~mm}$ length, and $0.5 \mathrm{~mm}$ thickness, while the ring parts have $15.2 \mathrm{~mm}$ diameter, $10 \mathrm{~mm}$ width and $0.5 \mathrm{~mm}$ thickness. The PZT patch has $15 \mathrm{~mm}$ length, $5 \mathrm{~mm}$ width, and $0.508 \mathrm{~mm}$ thickness. The PZT is made of the piezoelectric material PZT-5A while the substrate is made of aluminum. The PZT's 
location is deviated by $1.5 \mathrm{~mm}$ from the middle of the flexural section. The distance from the anchor block to the EMI sensor is $40 \mathrm{~mm}$ (see Figure 6b).
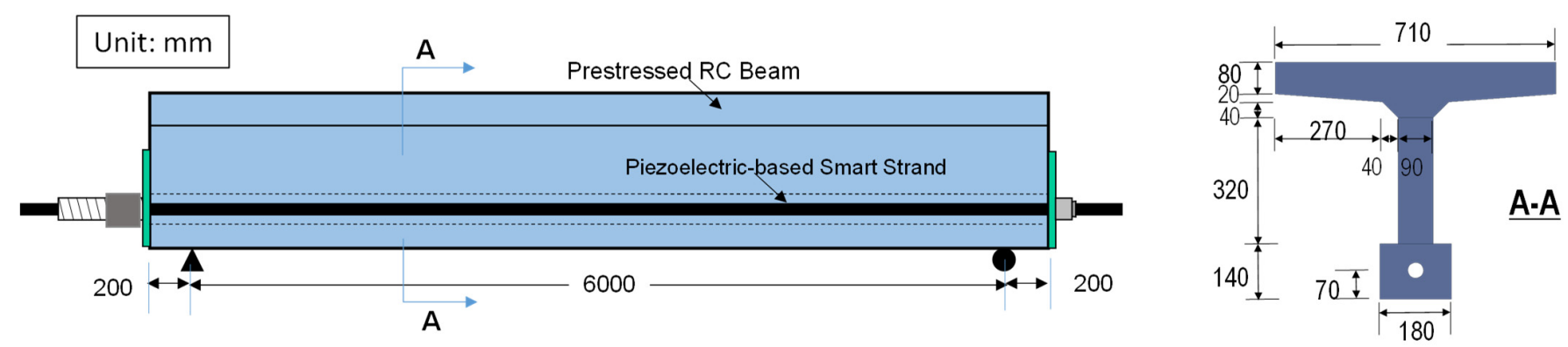

(a) Dimensional parameters of the post-tensioned RC beam

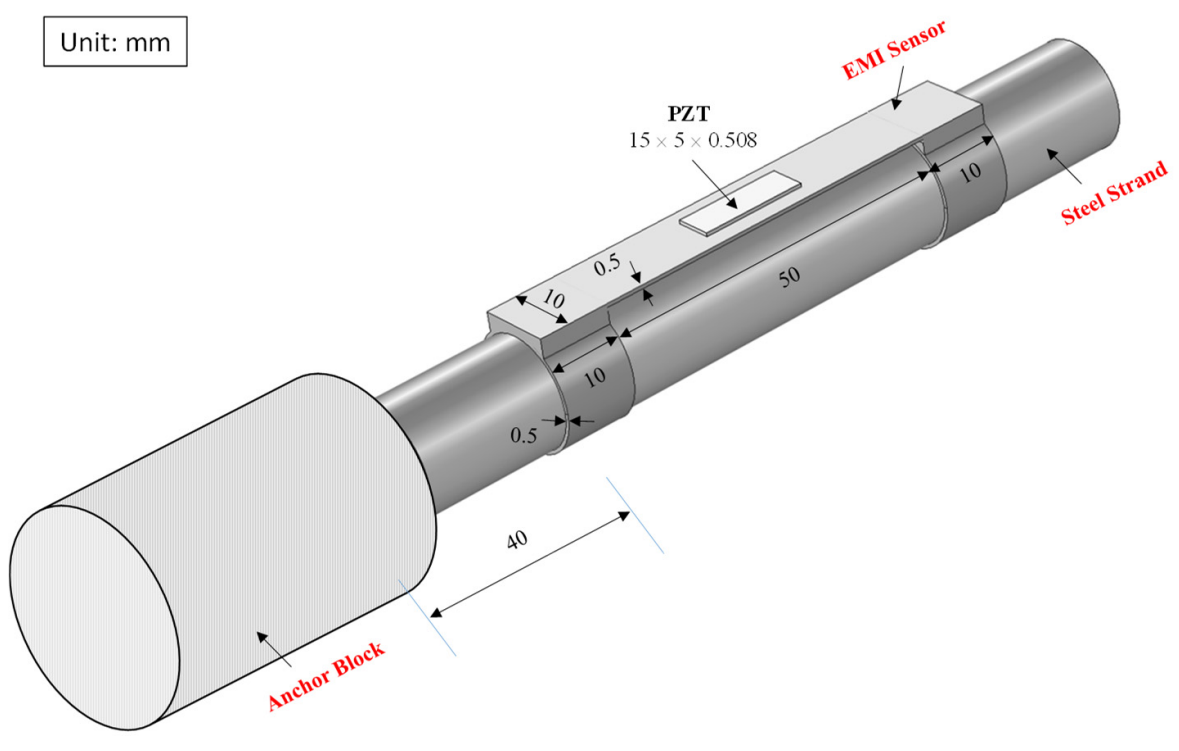

(b) Dimensional parameters of the piezoelectric-based smart strand

Figure 6. Geometric parameters of the post-tensioned RC beam and the smart strand.

After installing the smart strand, a PS force of 1 ton (PS1) was initially introduced into the RC beam to set the initial condition for the EMI sensor. Next, the smart strand was pre-stressed up to 2 tons (PS2), 3 tons (PS3), 4 tons (PS4), and 5 tons (PS5) to simulate the change in the PS force. After reaching the desired PS level, the EMI response of the smart strand was measured in a frequency range of $0.5-10.5 \mathrm{kHz}$ (501 swept points, a frequency interval of $20 \mathrm{~Hz}$ ). During the EMI measurement, the ambient temperature surrounding the test structure was controlled and nearly unchanged to minimize the effect of temperature change on the EMI response of the smart strand.

\subsection{Experimental EMI Response of the Smart Strand}

The real part of the EMI response measured under different PS forces is shown in Figure $7 \mathrm{a}$. In the frequency range of $0.5-10.5 \mathrm{kHz}$, we observed four resonant zones: 0.5-1.2 kHz (Peak 1, see Figure 7b), 2-3 kHz (Peak 2, see Figure 7c), 4.5-6.5 kHz (Peak 3, see Figure 7d), and 7.7-9.5 kHz (Peak 4, see Figure 7e) corresponding to the first, second, third, and fourth bending motions of the EMI sensor. It is found that Peak 2 had an inconsiderable magnitude compared to all four peaks because the PZT was located near the middle of the flexural section where the modal displacement of the second mode was zero. The figure shows that the resonant peaks were exceptionally sensitive to the PS force. In particular, the resonant peaks were sensitively shifted to the rightward as the PS force 
was increased, suggesting the increased natural frequencies of the EMI sensor, as explained by Equation (4).

(a)

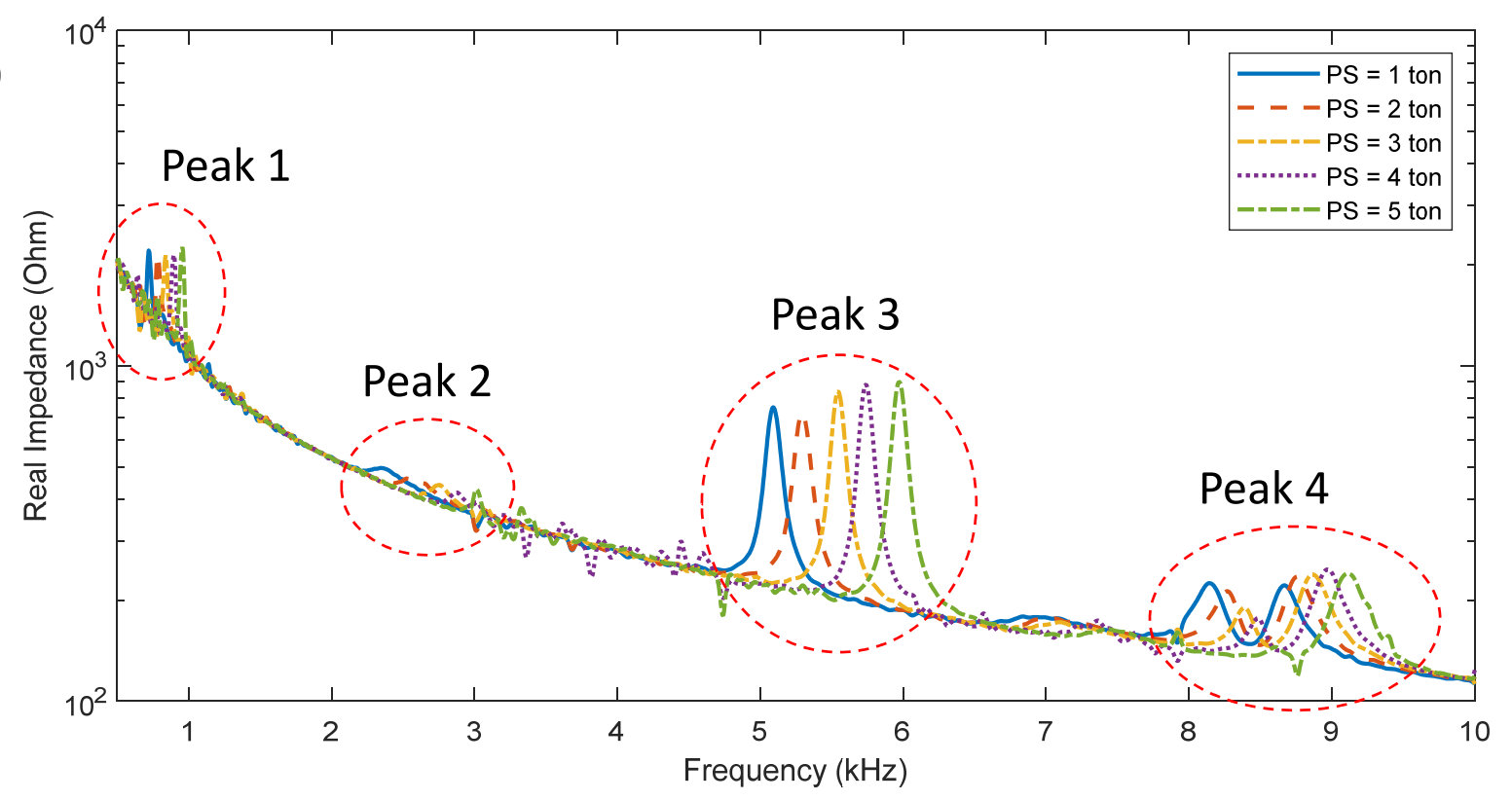

(b)

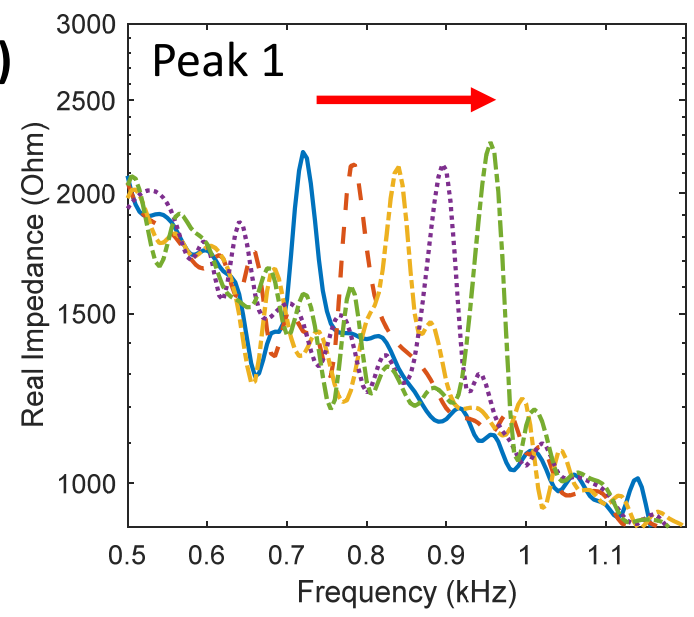

(d)

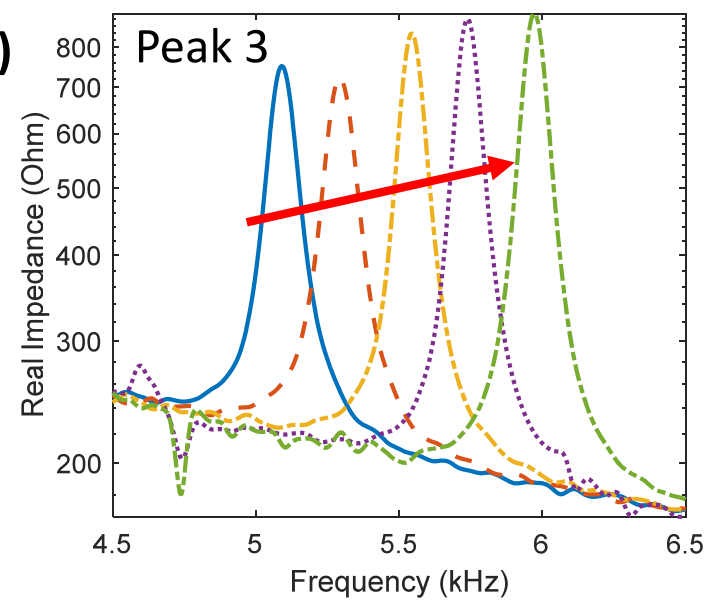

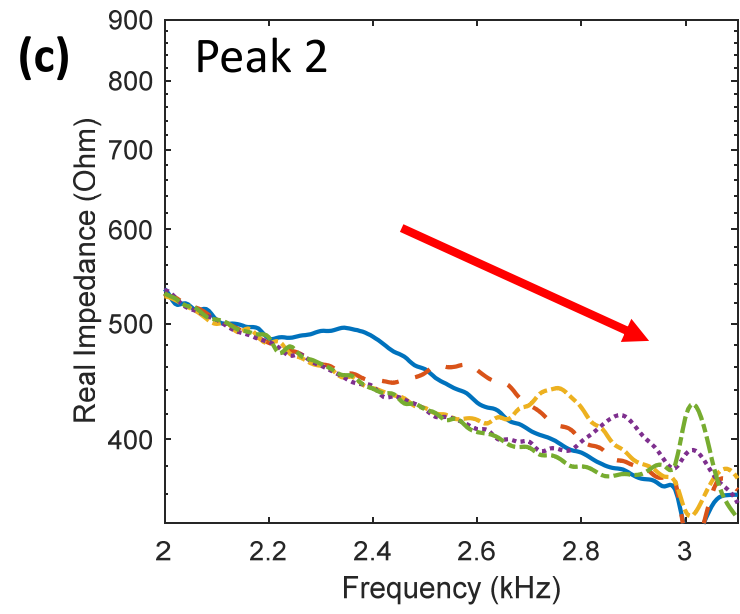

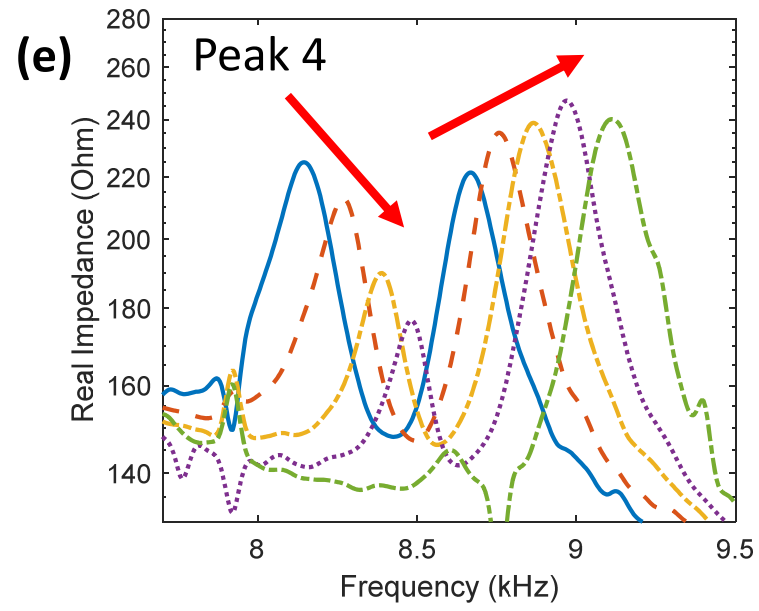

Figure 7. Cont. 
(f)

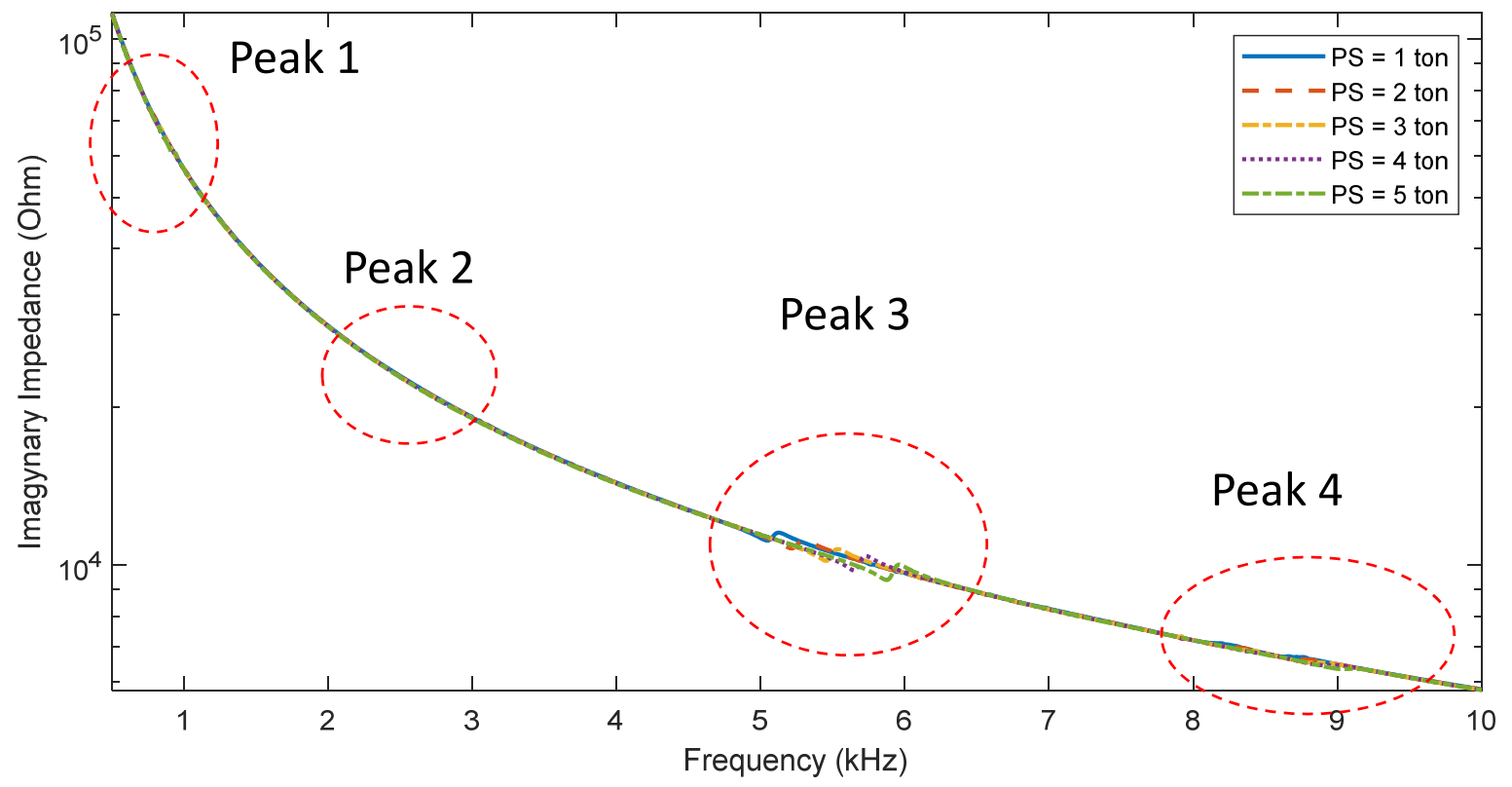

(g)

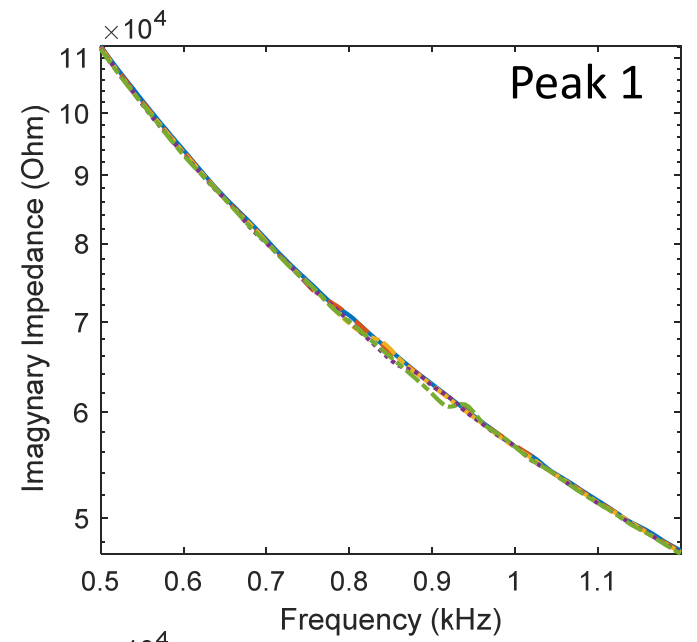

(h)

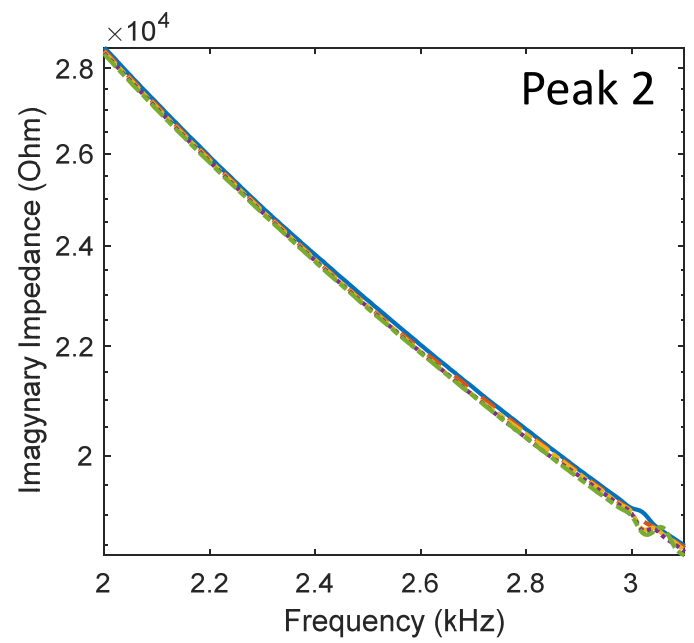

(i)
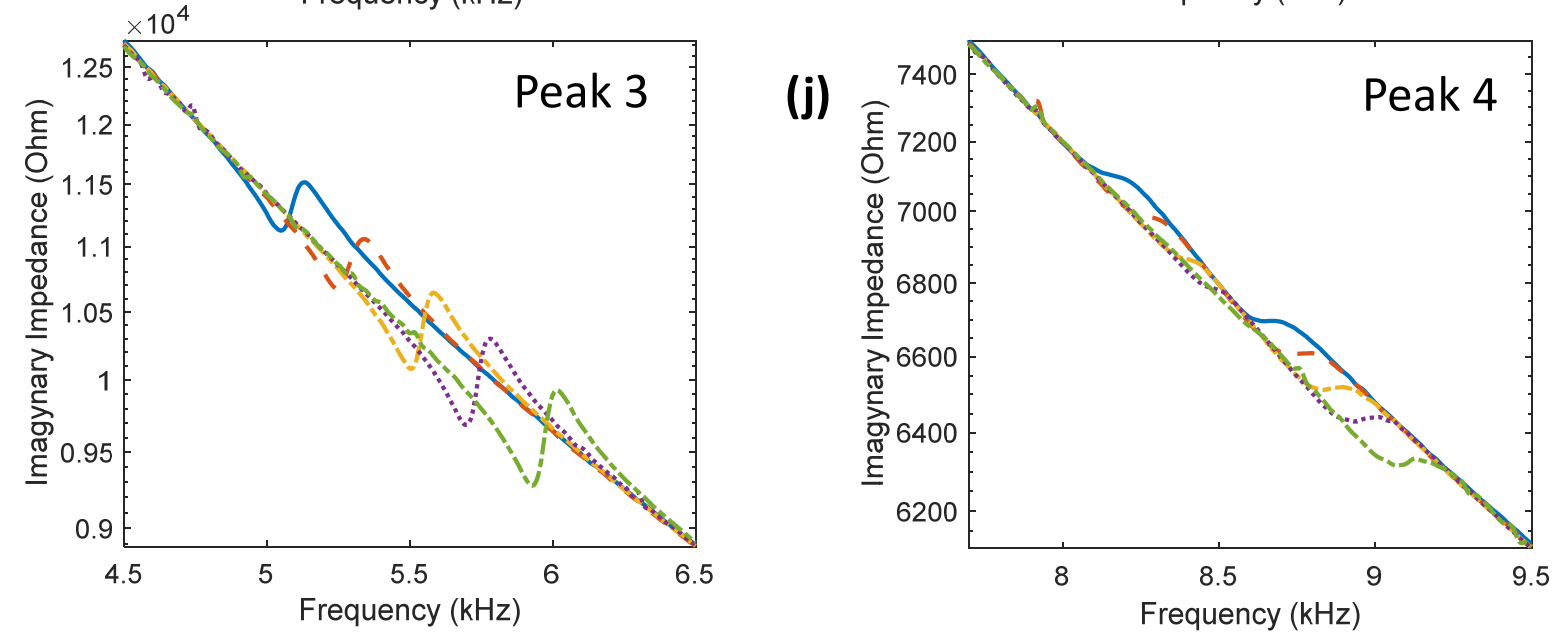

Figure 7. Resonant EMI responses of the smart strand (a-e) Real part; $(\mathbf{f}-\mathbf{j})$ : Imaginary part.

The imaginary part of the EMI response corresponding to five PS levels is depicted in Figure 7f. This also showed variations under the effect of the PS force. However, the variations were different for each impedance peak. Specifically, the imaginary parts of Peak 1 and Peak 2 showed ignorable changes while the remainder had considerable 
variations, as shown in Figure 7g-j. It is found that the curves of the imaginary part agreed well with each other, suggesting that there was no damage occurred in the PZT patch and its bonding layer during the prestressing process. The result confirmed the stability of the designed smart strand when it is implemented in a realistic structure.

The changes in the peak frequency and the peak magnitude were analyzed in Figure $8 a, b$, respectively. While the peak magnitude showed inconsistent changing trends for all peaks, the peak frequency showed a consistent increase with the PS force. Among four peaks, Peak 1 had the least frequency shift while Peak 3 experienced the most frequency variation.

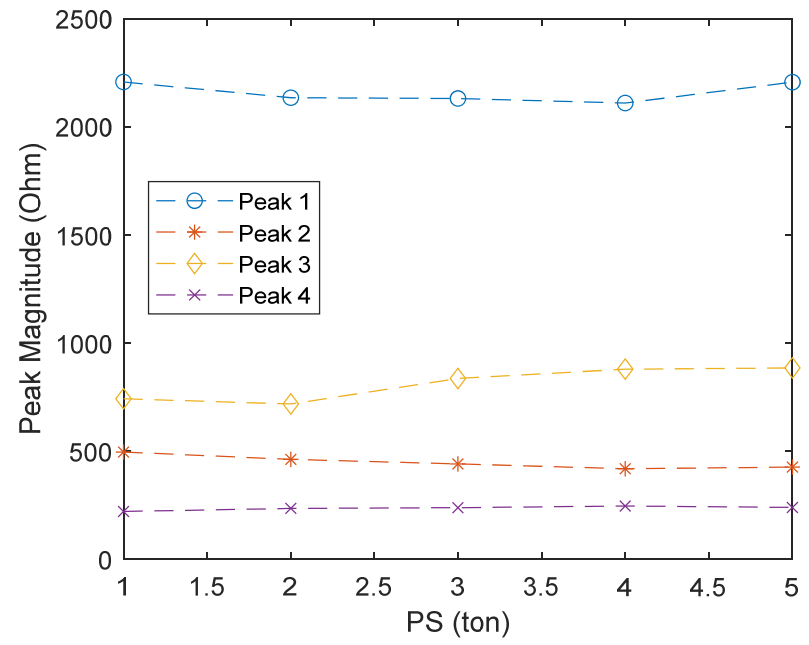

(a) Peak magnitude

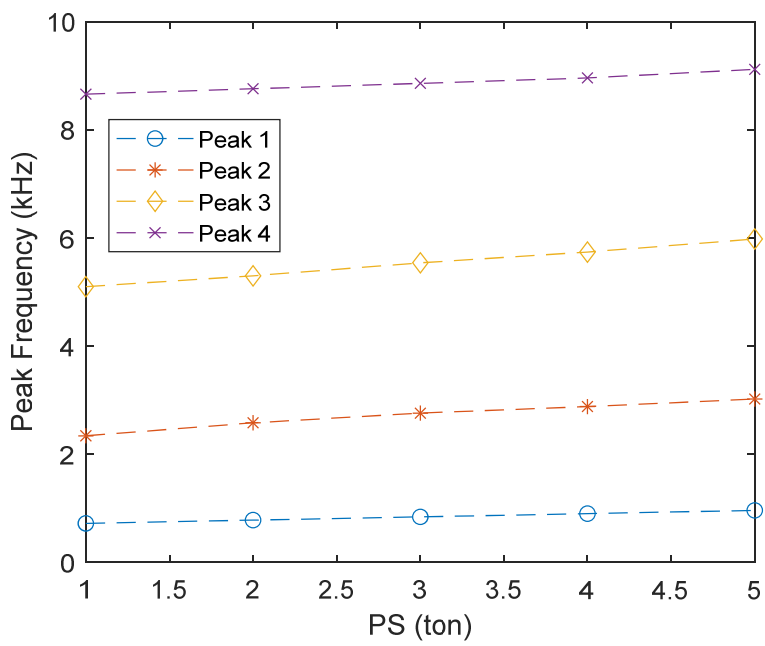

(b) Peak frequency

Figure 8. Changes in magnitudes and frequencies of the resonant peaks.

\subsection{PS Monitoring Using EMI Features}

For PS force monitoring, two EMI features, RMSD and CCD metrics, were extracted from the real part of the EMI response. It should be noted that the two metrics have different behaviors. Particularly, while the RMSD metric is sensitive to both vertical shift (i.e., magnitude change) and horizontal shift (i.e., frequency change) of the EMI response, the CCD metric is more sensitive to the change in the horizontal shift $[55,56]$.

The RMSD and CCD metrics were calculated using the whole frequency band of $0.5-10.5 \mathrm{kHz}$, as shown in Figure 9a, b, respectively. The results showed that both metrics were increased with increment in the PS force. As compared with the RMSD metric, the CCD showed a more linear change with an increase in PS force. The CCD also showed clearer gaps between two PS levels than the RMSD. This observation suggests that the CCD metric can be a better indicator for PS force monitoring through the piezoelectric-based smart strand.

Next, we extracted the RMSD and CCD metrics for the four impedance peaks (Peak 1Peak 4), as plotted in Figure 10a-d. Overall, the metrics were proportional to the increase of PS force for all peaks. The RMSD metric showed nonlinear changing trends in most cases while the CCD metric tended to linearly vary with the PS force in cases of Peak 2 and Peak 4. This result again confirms the reliability of the CCD metric for PS force monitoring using the smart strand. 


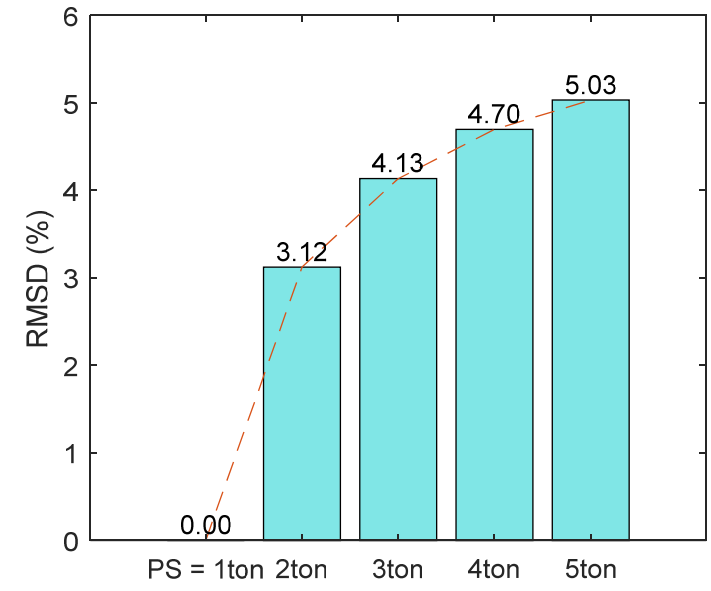

(a) RMSD metric

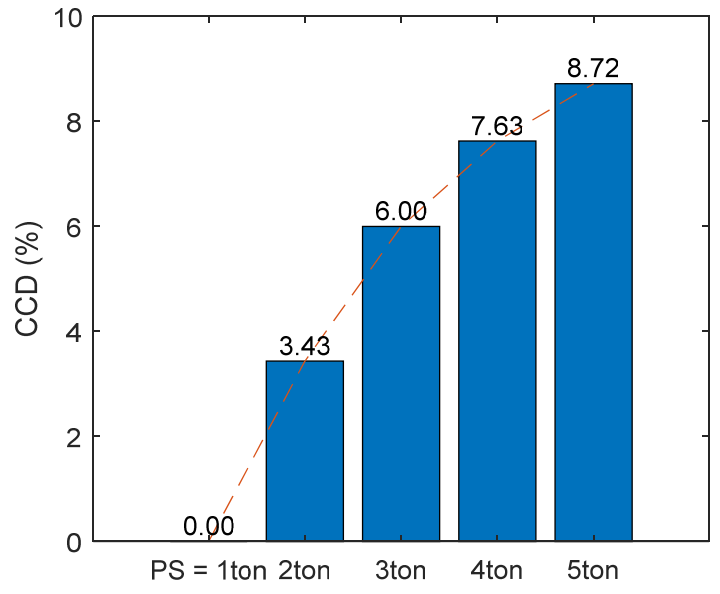

(b) CCD metric

Figure 9. Changes in EMI features of the whole frequency band.

RMSD Index

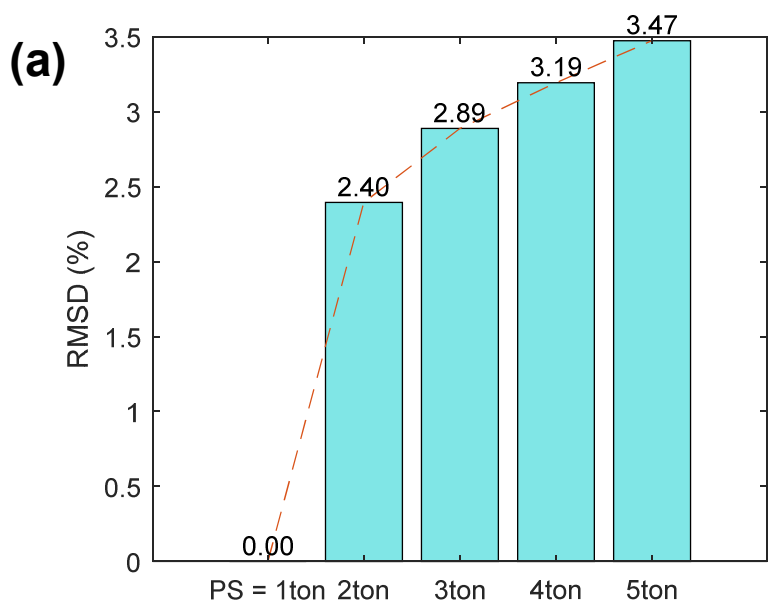

(b)

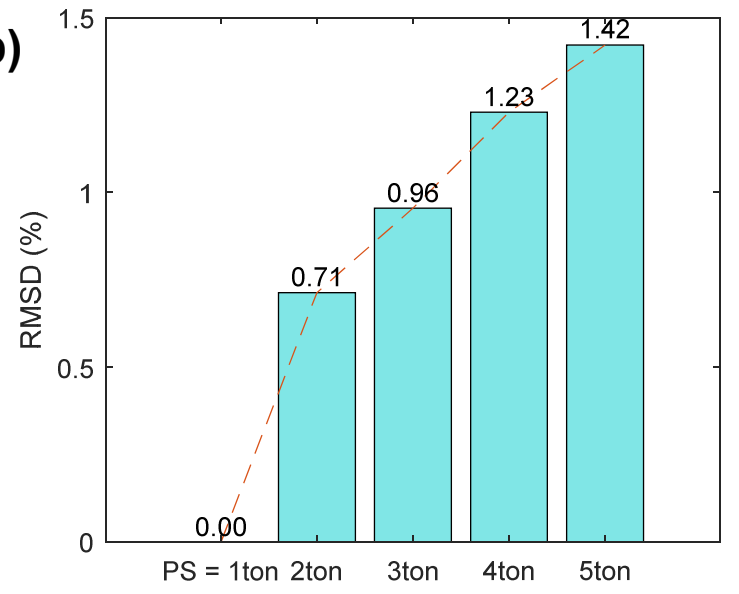

CCD Index
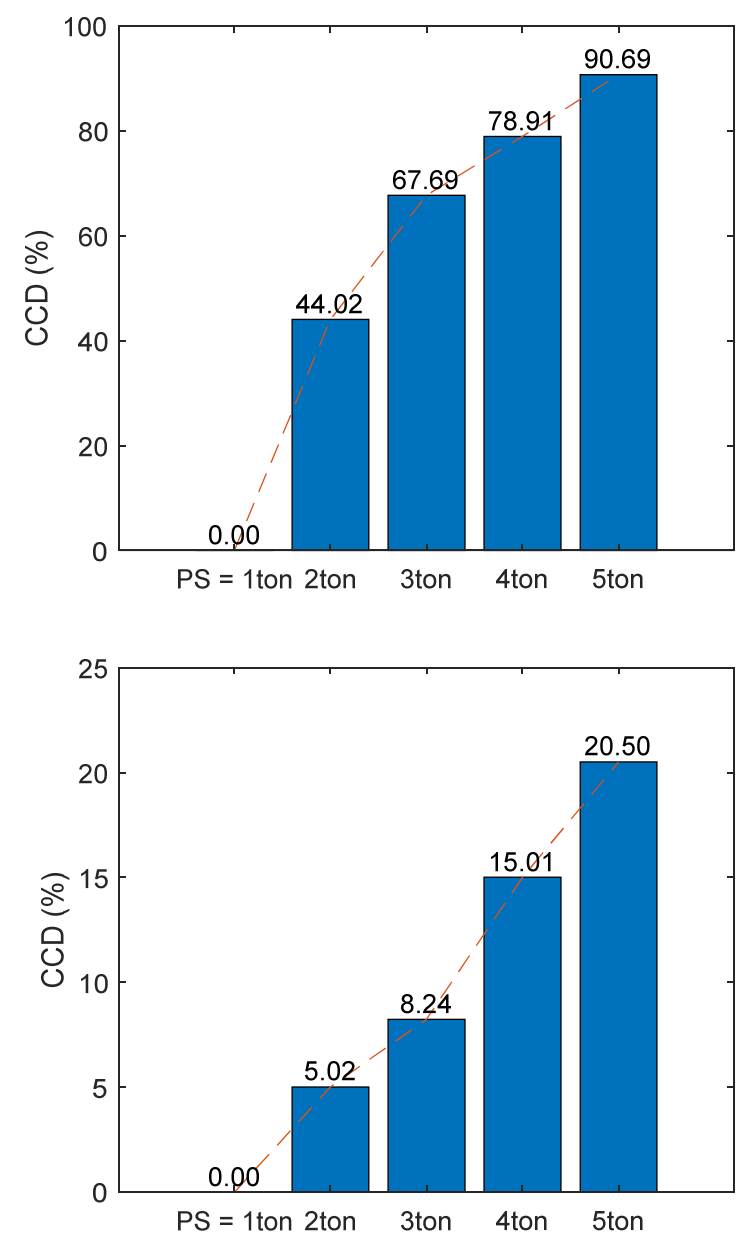

Figure 10. Cont. 

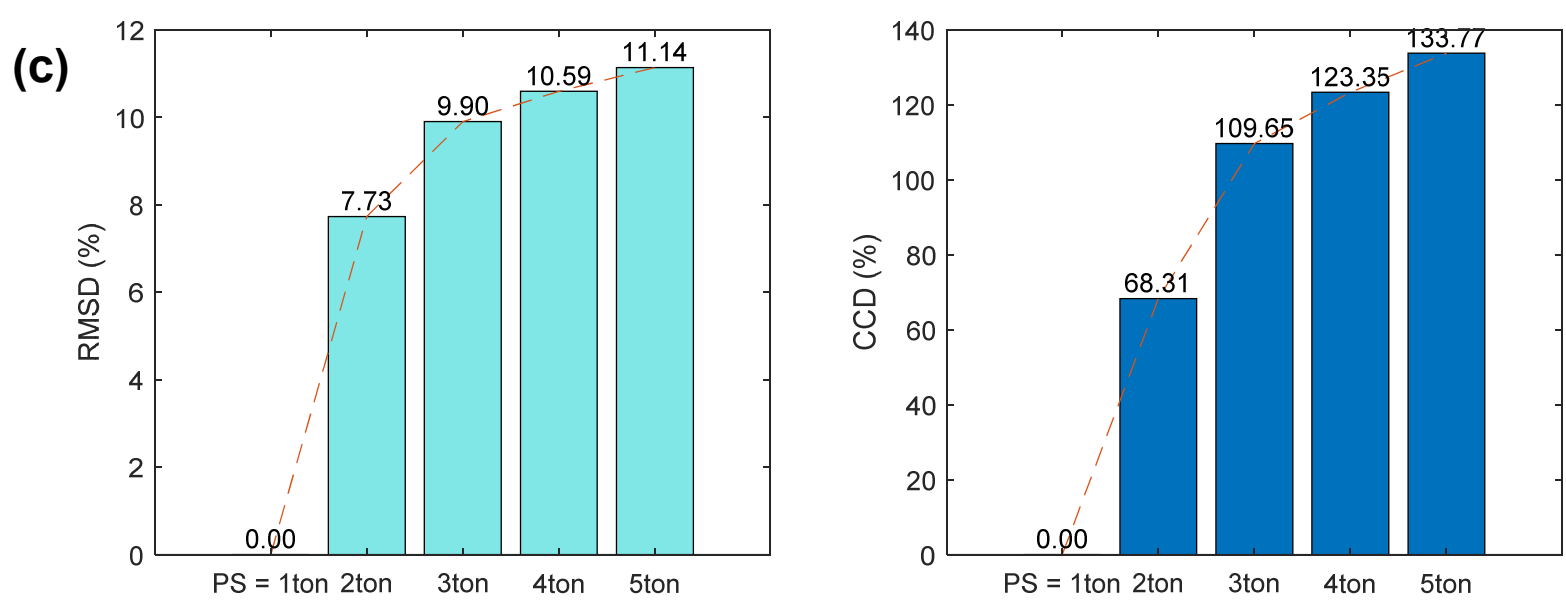

(d)
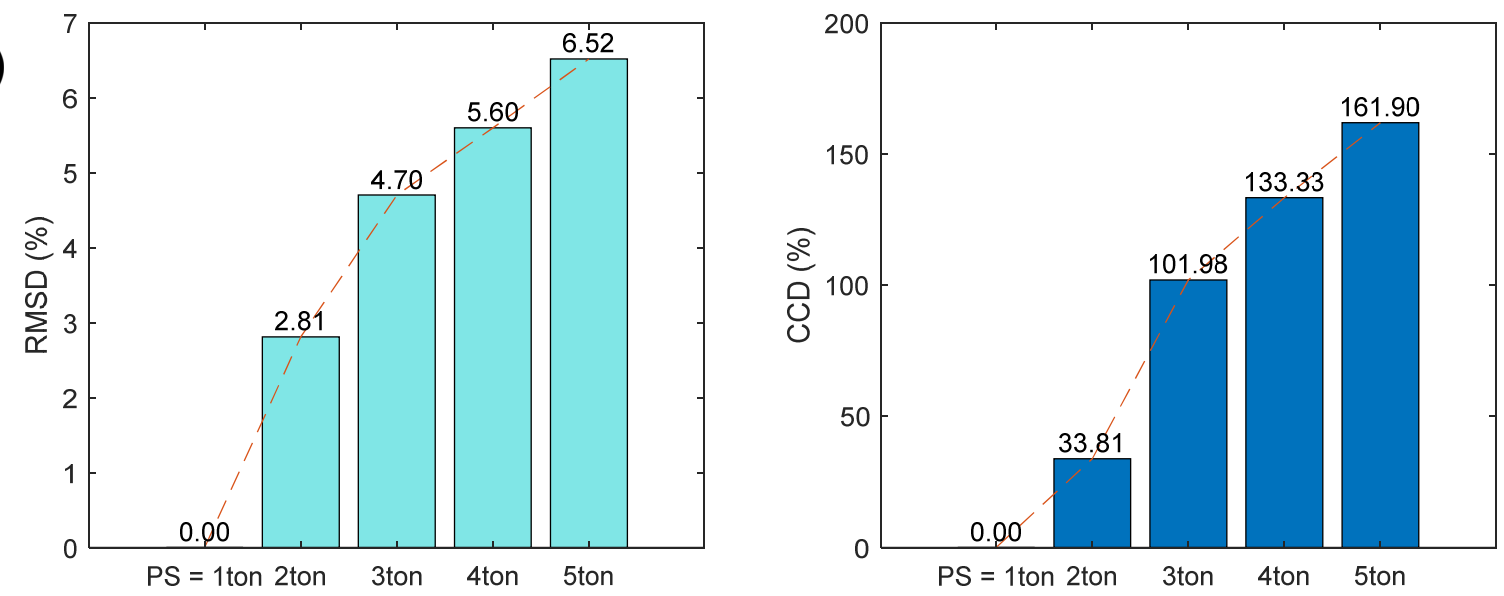

Figure 10. Changes in EMI features of the resonant bands (a) Peak 1; (b) Peak 2; (c) Peak 3; (d) Peak 4.

\subsection{PS Prediction Based on Regression Analysis}

The relationships between the PS change and the RMSD and CCD metrics are analyzed using linear approximation functions, as shown in Figure 11a,b, respectively. We considered different frequency ranges ranging from the narrow ones (i.e., Peak 1-Peak 4) to the whole frequency band (i.e., all peaks) to select the best relationship for PS force prediction. It is found that Peak 4 showed the least scatter of the RMSD data points around the fitted regression line (see Figure 11a) while the CCD data points of Peak 2 had the best regression line (see Figure 11b).

From the above analyses, two empirical formulas were selected to predict the PS force change $(\triangle P S)$, as follows:

$$
\begin{aligned}
\Delta P S(\text { ton }) & =\frac{\Delta \operatorname{RMSD}(\%)}{1.8357} \\
\Delta P S(\text { ton }) & =\frac{\Delta \operatorname{CCD}(\%)}{4.9512}
\end{aligned}
$$

Using Equations (7) and (8), the PS changes in the prestressed RC beam were estimated, as shown in Figure 12. The prediction results for the two metrics agreed relatively well with the inflicted values. Excepting the considerable error of the prediction in the case PS3, the PS changes in other cases were well predicted, with only ignorable errors, by the CCD-based regression. The obtained result shows that the CCD metric was a good indicator to detect the PS force change in the smart strand. 


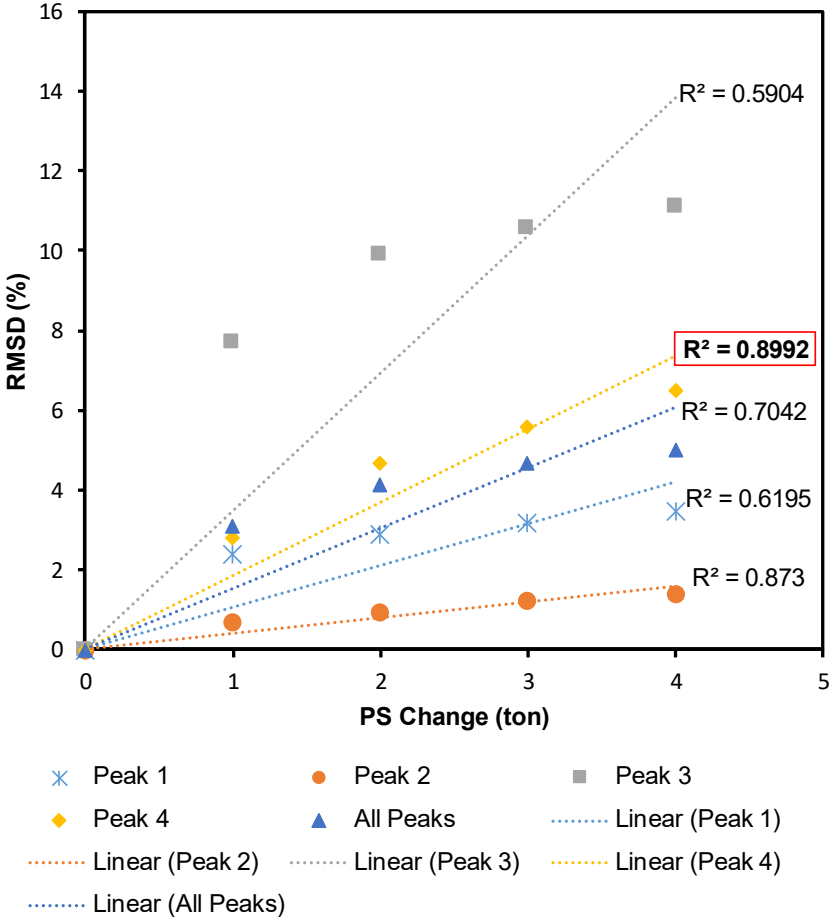

(a) RMSD metric

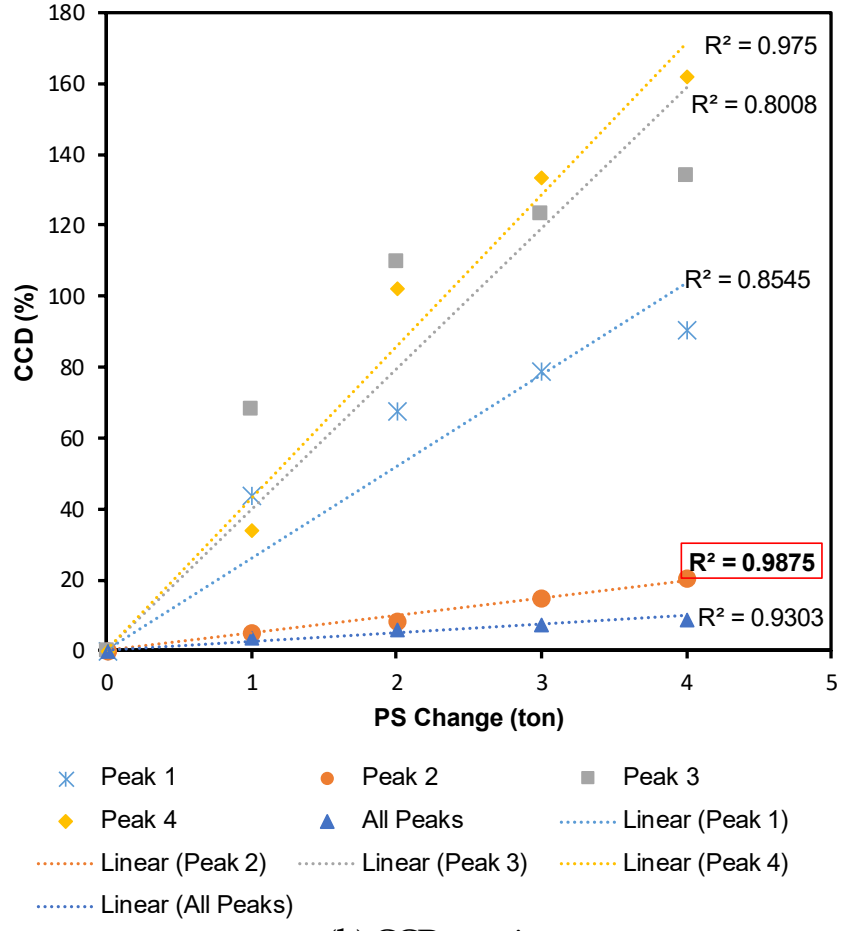

(b) CCD metric

Figure 11. Linear regression analyses of EMI features.

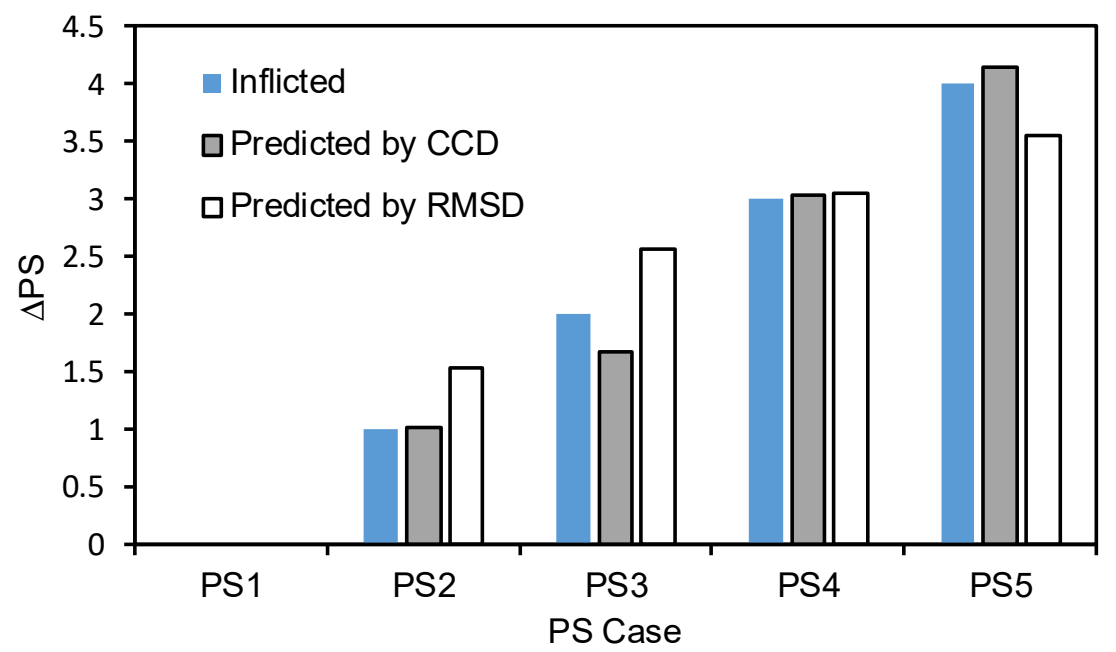

Figure 12. Prediction of PS force change using linear regression.

In summary, the proposed smart strand is cost-effective due to the use of a cheap and easy-fabrication EMI sensor. Additionally, the EMI sensor has low resonant frequencies that are compatible with low-cost wireless EMI sensing devices. Moreover, the EMI sensor shows a high sensitivity to the PS changes with clear shifts of resonant impedance peaks.

\section{Summary and Conclusions}

In the present work, the concept of a piezoelectric-based smart strand was developed for PS force monitoring of a post-tensioned RC beam. To prepare the smart strand, a highsensitivity EMI sensor was designed and embedded in a steel strand. The experimental feasibility of the proposed smart strand was evaluated on a realistic prestressed RC beam under changes in the PS force. The EMI response of the smart strand was recorded and the EMI features (i.e., RMSD and CCD) were extracted for PS force monitoring and prediction. 
From the experimental investigation, the following conclusions can be drawn, as follows: (1) The real part of the EMI signals had four resonant peaks that were sensitively varied with the PS force. The resonant peaks were shifted to the rightward as the PS force was increased, suggesting an increase in natural frequencies of the EMI sensor. (2) The imaginary part of the EMI response showed consistent curves during the prestressing process, indicating the stable functionality of the designed smart strand. (3) The EMI features (RMSD and CCD) proportionally increased with the PS force. The CCD showed a more linear change with an increase of the PS force than the RMSD metric. (4) The prestress change in the prestressed $\mathrm{RC}$ beam could be predicted by using linear regression models of the EMI features. It is found that the CCD metric was a better indicator for detecting the PS force change in the smart strand.

The main objective of this study was to preliminarily verify the feasibility of the conceptual design of the piezoelectric-based smart strand. Our research group is going to optimize the geometry of the smart strand and develop new algorithms to better predict the PS force using the EMI response. We will also focus on developing a new EMI model that can accurately predict the EMI response of the smart strand. The in-situ performance of the proposed technique will be further investigated under the effect of environmental variation.

Author Contributions: Conceptualization, T.-C.H., D.-D.H. and T.-C.L.; methodology, T.-C.H., D.D.H. and T.-C.L.; validation, T.-C.H., D.-D.H., T.-H.N. and T.T.V.P.; formal analysis, T.-C.H., T.-H.N. and T.T.V.P.; writing-original draft preparation, T.-C.H., T.-C.L., T.-H.N. and T.T.V.P.; writingreview and editing, T.-C.H. and D.-D.H. All authors have read and agreed to the published version of the manuscript.

Funding: This research received no external funding.

Data Availability Statement: The data are available upon request.

Acknowledgments: We acknowledge the support of time and facilities from Ho Chi Minh City University of Technology (HCMUT), VNU-HCM for this study.

Conflicts of Interest: The authors declare no conflict of interest.

\section{References}

1. Abdel-Jaber, H.; Glisic, B. Monitoring of prestressing forces in prestressed concrete structures-An overview. Struct. Control Health Monit. 2019, 26, e2374. [CrossRef]

2. Chandrasekar, P.; Dayaratnam, P. Analysis of probability of failure of prestressed concrete beams. Build. Sci. 1975, 10, 161-167. [CrossRef]

3. Yuyama, S.; Yokoyama, K.; Niitani, K.; Ohtsu, M.; Uomoto, T. Detection and evaluation of failures in high-strength tendon of prestressed concrete bridges by acoustic emission. Constr. Build. Mater. 2007, 21, 491-500. [CrossRef]

4. Saiidi, M.; Douglas, B.; Feng, S. Prestress Force Effect on Vibration Frequency of Concrete Bridges. J. Struct. Eng. 1994, 120, 2233-2241. [CrossRef]

5. Kim, J.T.; Yun, C.B.; Ryu, Y.S.; Cho, H.M. Identification of prestress-loss in PSC beams using modal information. Struct. Eng. Mech. 2004, 17, 467-482. [CrossRef]

6. Wang, M.L.; Wang, G.; Zhao, Y. Application of EM stress sensors in large steel cables. In SPIE Smart Structures and Materials + Nondestructive Evaluation and Health Monitoring; SPIE: Bellingham, WA, USA, 2005; Volume 5765.

7. Jarosevic, A. Magnetoelastic Method of Stress Measurement in Steel. In Smart Structures: Requirements and Potential Applications in Mechanical and Civil Engineering; Holnicki-Szulc, J., Rodellar, J., Eds.; Springer: Dordrecht, The Netherlands, 1999 ; pp. 107-114.

8. Halvonik, J.; Dolnak, J.; Borzovič, V. Long-term Losses of Prestress in Precast Members Cast from HPC. Procedia Eng. 2013, 65, 81-86. [CrossRef]

9. Kwun, H.; Bartels, K.A.; Hanley, J.J. Effects of tensile loading on the properties of elastic-wave propagation in a strand. J. Acoust. Soc. Am. 1998, 103, 3370-3375. [CrossRef]

10. Chaki, S.; Bourse, G. Stress Level Measurement in Prestressed Steel Strands Using Acoustoelastic Effect. Exp. Mech. 2008, 49, 673. [CrossRef]

11. Onyemelukwe, O.U.; Kunnath, S.K. Field Measurement and Evaluation of Time-Dependent Losses in Prestressed Concrete Bridges; Report No. WPI 0510735; Florida Department of Transportation: Tallahassee, FL, USA, 1997.

12. Guo, T.; Chen, Z.; Lu, S.; Yao, R. Monitoring and analysis of long-term prestress losses in post-tensioned concrete beams. Measurement 2018, 122, 573-581. [CrossRef] 
13. Kim, S.T.; Park, Y.; Park, S.Y.; Cho, K.; Cho, J.R. A sensor-type PC strand with an embedded FBG sensor for monitoring prestress forces. Sensors 2015, 15, 1060-1070. [CrossRef]

14. Huynh, T.-C.; Kim, J.-T. FOS-Based Prestress Force Monitoring and Temperature Effect Estimation in Unbonded Tendons of PSC Girders. J. Aerosp. Eng. 2017, 30, B4016005. [CrossRef]

15. Kim, Y.S.; Sung, H.J.; Kim, H.W.; Kim, J.M. Monitoring of tension force load transfer of groundanchor by using optical FBG sensors embedded tendon. Smart Struct. Syst. 2011, 7, 303-317. [CrossRef]

16. Lee, S.; Chen, C.; Deshpande, V.V.; Lee, G.H.; Lee, I.; Lekas, M.; Gondarenko, A.; Yu, Y.J.; Shepard, K.; Kim, P.; et al. Electrically integrated SU-8 clamped graphene drum resonators for strain engineering. Appl. Phys. Lett. 2013, 102, 153101. [CrossRef]

17. Versaci, M.; Jannelli, A.; Morabito, F.C.; Angiulli, G. A Semi-Linear Elliptic Model for a Circular Membrane MEMS Device Considering the Effect of the Fringing Field. Sensors 2021, 21, 5237. [CrossRef] [PubMed]

18. Angiulli, G.; Jannelli, A.; Morabito, F.C.; Versaci, M. Reconstructing the membrane detection of a 1D electrostatic-driven MEMS device by the shooting method: Convergence analysis and ghost solutions identification. Comput. Appl. Math. 2018, 37, 4484-4498. [CrossRef]

19. Huynh, T.-C.; Kim, J.-T. Quantification of temperature effect on impedance monitoring via PZT interface for prestressed tendon anchorage. Smart Mater. Struct. 2017, 26, 125004. [CrossRef]

20. Huynh, T.-C.; Kim, J.-T. Quantitative damage identification in tendon anchorage via PZT interface-based impedance monitoring technique. Smart Struct. Syst. 2017, 20, 181-195.

21. Ho, D.D.; Lee, P.Y.; Nguyen, K.D.; Hong, D.S.; Lee, S.Y.; Kim, J.T.; Shin, S.W.; Yun, C.B.; Shinozuka, M. Solar-powered multi-scale sensor node on Imote2 platform for hybrid SHM in cable-stayed bridge. Smart Struct. Syst. 2012, 9, 145-164. [CrossRef]

22. Min, J.; Yun, C.-B.; Hong, J.-W. An electromechanical impedance-based method for tensile force estimation and damage diagnosis of post-tensioning systems. Smart Struct. Syst. 2016, 17, 107-122. [CrossRef]

23. Giurgiutiu, V. Chapter 10-High-Frequency Vibration SHM with PWAS Modal Sensors-the Electromechanical Impedance Method. In Structural Health Monitoring with Piezoelectric Wafer Active Sensors, 2nd ed.; Giurgiutiu, V., Ed.; Academic Press: Oxford, UK, 2014; pp. 509-572.

24. Ho, D.D.; Huynh, T.C.; Luu, T.H.T.; Le, T.C. Electro-Mechanical Impedance-Based Prestress Force Monitoring in Prestressed Concrete Structures. In Structural Health Monitoring and Engineering Structures; Springer: Singapore, 2021; pp. $413-423$.

25. Chen, Y.; Xue, X. Advances in the Structural Health Monitoring of Bridges Using Piezoelectric Transducers. Sensors 2018, $18,4312$. [CrossRef]

26. Park, S.; Shin, H.-H.; Yun, C.-B. Wireless impedance sensor nodes for functions of structural damage identification and sensor self-diagnosis. Smart Mater. Struct. 2009, 18, 055001. [CrossRef]

27. Park, J.-H.; Huynh, T.-C.; Kim, J.-T. Temperature effect on wireless impedance monitoring in tendon anchorage of prestressed concrete girder. Smart Struct. Syst. 2015, 15, 1159-1175. [CrossRef]

28. Perera, R.; Pérez, A.; García-Diéguez, M.; Zapico-Valle, J.L. Active Wireless System for Structural Health Monitoring Applications. Sensors 2017, 17, 2880. [CrossRef] [PubMed]

29. Mascarenas, D.L.; Todd, M.D.; Park, G.; Farrar, C.R. Development of an impedance-based wireless sensor node for structural health monitoring. Smart Mater. Struct. 2007, 16, 2137. [CrossRef]

30. Min, J.; Park, S.; Yun, C.B.; Song, B. Development of a low-cost multifunctional wireless impedance sensor node. Smart Struct. Syst. 2010, 6, 689-709.

31. Overly, T.G.; Park, G.; Farinholt, K.M.; Farrar, C.R. Development of an extremely compact impedance-based wireless sensing device. Smart Mater. Struct. 2008, 17, 065011. [CrossRef]

32. Kim, J.T.; Park, J.H.; Hong, D.S.; Park, W.S. Hybrid health monitoring of prestressed concrete girder bridges by sequential vibration-impedance approaches. Eng. Struct. 2010, 32, 115-128. [CrossRef]

33. Nguyen, K.-D.; Kim, J.-T. Smart PZT-interface for wireless impedance-based prestress-loss monitoring in tendon-anchorage connection. Smart Struct. Syst. 2012, 9, 489-504. [CrossRef]

34. Le, T.-C.; Ho, D.-D.; Huynh, T.-C. Anchor Force Monitoring Using Impedance Technique with Single-Point Mount Lead-ZirconateTitanate Interface: A Feasibility Study. Buildings 2021, 11, 382. [CrossRef]

35. Huynh, T.-C.; Kim, J.-T. Impedance-based cable force monitoring in tendon-anchorage using portable PZT-interface technique. Math. Probl. Eng. 2014, 2014. [CrossRef]

36. Lim, Y.Y.; Soh, C.K. Effect of varying axial load under fixed boundary condition on admittance signatures of electromechanical impedance technique. J. Intell. Mater. Syst. Struct. 2012, 23, 815-826. [CrossRef]

37. Ong, C.W.; Yang, Y.; Naidu, A.S.K.; Lu, Y.; Soh, C.K. Application of the electromechanical impedance method for the identification of in-situ stress in structures. In SPIE's International Symposium on Smart Materials, Nano-, and Micro- Smart Systems; SPIE: Bellingham, WA, USA, 2002; Volume 4935.

38. Dang, N.-L.; Huynh, T.-C.; Kim, J.-T. Local strand-breakage detection in multi-strand anchorage system using an impedance-based stress monitoring method-Feasibility study. Sensors 2019, 19, 1054. [CrossRef] [PubMed]

39. Dang, N.L.; Huynh, T.C.; Pham, Q.Q.; Lee, S.Y.; Kim, J.T. Damage-sensitive impedance sensor placement on multi-strand anchorage based on local stress variation analysis. Struct. Control Health Monit. 2020, 27, e2547. [CrossRef]

40. Na, W.S.; Baek, J. A Review of the Piezoelectric Electromechanical Impedance Based Structural Health Monitoring Technique for Engineering Structures. Sensors 2018, 18, 1307. [CrossRef] [PubMed] 
41. Wang, C.; Wang, N.; Ho, S.C.; Chen, X.; Pan, M.; Song, G. Design of a Novel Wearable Sensor Device for Real-Time Bolted Joints Health Monitoring. IEEE Internet Things J. 2018, 5, 5307-5316. [CrossRef]

42. Annamdas, V.G.M.; Radhika, M.A.; Yang, Y. Easy installation method of piezoelectric (PZT) transducers for health monitoring of structures using electro-mechanical impedance technique. In Sensors and Smart Structures Technologies for Civil, Mechanical, and Aerospace Systems 2009; SPIE: Bellingham, WA, USA, 2009; Volume 7292, p. 729227.

43. Na, S.; Lee, H.-K. Resonant frequency range utilized electro-mechanical impedance method for damage detection performance enhancement on composite structures. Compos. Struct. 2012, 94, 2383-2389. [CrossRef]

44. Huynh, T.-C.; Lee, K.-S.; Kim, J.-T. Local dynamic characteristics of PZT impedance interface on tendon anchorage under prestress force variation. Smart Struct. Syst. 2015, 15, 375-393. [CrossRef]

45. Liang, C.; Sun, F.P.; Rogers, C.A. Coupled Electro-Mechanical Analysis of Adaptive Material Systems — Determination of the Actuator Power Consumption and System Energy Transfer. J. Intell. Mater. Syst. Struct. 1994, 5, 12-20. [CrossRef]

46. Park, G.; Sohn, H.; Farrar, C.R.; Inman, D.J. Overview of piezoelectric impedance-based health monitoring and path forward. Shock. Vib. Dig. 2003, 35, 451-464. [CrossRef]

47. Huynh, T.-C.; Dang, N.-L.; Kim, J.-T. Advances and challenges in impedance-based structural health monitoring. Struct. Monit. Maint. 2017, 4, 301-329.

48. Park, G.; Farrar, C.R.; di Scalea, F.L.; Coccia, S. Performance assessment and validation of piezoelectric active-sensors in structural health monitoring. Smart Mater. Struct. 2006, 15, 1673. [CrossRef]

49. Nguyen, B.P.; Tran, Q.H.; Nguyen, T.T.; Pradhan, A.M.S.; Huynh, T.C. Understanding Impedance Response Characteristics of a Piezoelectric-Based Smart Interface Subjected to Functional Degradations. Complexity 2021, 2021. [CrossRef]

50. Park, G.; Farrar, C.R.; Rutherford, A.C.; Robertson, A.N. Piezoelectric Active Sensor Self-Diagnostics Using Electrical Admittance Measurements. J. Vib. Acoust. 2006, 128, 469-476. [CrossRef]

51. Park, S.; Park, G.; Yun, C.B.; Farrar, C.R. Sensor Self-diagnosis Using a Modified Impedance Model for Active Sensing-based Structural Health Monitoring. Struct. Health Monit. 2009, 8, 71-82. [CrossRef]

52. Sun, F.P.; Chaudhry, Z.; Liang, C.; Rogers, C.A. Truss Structure Integrity Identification Using PZT Sensor-Actuator. J. Intell. Mater. Syst. Struct. 1995, 6, 134-139. [CrossRef]

53. Jothi Saravanan, T.; Balamonica, K.; Bharathi Priya, C.; Gopalakrishnan, N.; Murthy, S.G.N. Piezoelectric EMI-Based Monitoring of Early Strength Gain in Concrete and Damage Detection in Structural Components. J. Infrastruct. Syst. 2017, 23, 04017029. [CrossRef]

54. Zagrai, A.N.; Giurgiutiu, V. Electro-Mechanical Impedance Method for Crack Detection in Thin Plates. J. Intell. Mater. Syst. Struct. 2001, 12, 709-718. [CrossRef]

55. Wandowski, T.; Malinowski, P.; Radzienski, M.; Opoka, S.; Ostachowicz, W. Methods for Assessment of Composite Aerospace Structures. In Smart Structures and Materials: Selected Papers from the 7th ECCOMAS Thematic Conference on Smart Structures and Materials; Araujo, A.L., Soares, C.A.M., Eds.; Springer International Publishing: Cham, Switzerland, 2017; pp. $227-244$.

56. Baptista, F.G.; Budoya, D.E.; De Almeida, V.A.; Ulson, J.A.C. An Experimental Study on the Effect of Temperature on Piezoelectric Sensors for Impedance-Based Structural Health Monitoring. Sensors 2014, 14, 1208-1227. [CrossRef] [PubMed] 